\title{
Extensive Odontogenic Myxoma of the Maxilla: A Case Report and Review of Literature
}

\author{
Sally Nguyen', Simon-Pierre Charbonneau' ${ }^{2}$, Julien E. Ghannoum², Eric Bissada1 \\ ${ }^{1}$ Department of Otolaryngology and Head \& Neck Surgery, Centre Hospitalier de l'Université de Montréal, \\ Montreal, Canada \\ ${ }^{2}$ Department of Stomatology, Centre Hospitalier de l'Université de Montréal, Montreal, Canada \\ Email: oralpathology@hotmail.com
}

Received 24 September 2014; revised 21 October 2014; accepted 11 November 2014

Copyright (C) 2014 by authors and Scientific Research Publishing Inc.

This work is licensed under the Creative Commons Attribution International License (CC BY).

http://creativecommons.org/licenses/by/4.0/

c) (i) Open Access

\begin{abstract}
Odontogenic myxomas (OM), also called odontogenic fibromyxomas, are rare tumours of the jawbones. They are benign tumours that can be locally invasive and aggressive, but seldom undergo malignant transformation and do not give rise to metastases. They are often asymptomatic and present as painless swelling. We present herein the case of a 24 -year-old patient, with an incidental finding of a maxillary lesion. The lesion expanded to the surrounding soft tissues of the face, the maxillary sinus, the nasal cavity and the ethmoidal cells. After confirmation of $\mathrm{OM}$ on biopsy, the patient underwent an extended right radical en bloc maxillectomy with immediate reconstruction of the inferior orbital rim. A literature review of clinical symptoms, radiological presentation, differential diagnosis and surgical management of $O M$ is discussed.
\end{abstract}

\section{Keywords}

Odontogenic Myxoma, Odontogenic Fibromyxoma, Maxilla

\section{Introduction}

Odontogenic myxomas (OM) are benign tumours first described in the literature by Thoma and Goldman in 1947 [1]. According to the World Health Organization (WHO), they originate from odontogenic ectomesenchyme, with or without odontogenic epithelium [2] [3]. Before the reclassification of odontogenic keratocysts as tumours, OM represented between $0.5 \%$ to $17 \%$ of all odontogenic tumours and were the third most frequent odontogenic tumours, after odontomas and ameloblastomas [3]-[5]. OMs are more common in women and gen- 
erally occur in the second to forth decades of life. They are rare in patients under the age of 10 or over the age of 50 [5]. They have been associated with unerupted teeth or a developmentally absent tooth [6]. Two thirds of OMs involve the mandible, whereas the remainder involves the maxilla. The most common affected site is the posterior mandible [3] [7] [8]. They can be locally invasive and aggressive, but are believed by some not to undergo malignant transformation nor give rise to metastases [9]. Odontogenic myxomas are generally asymptomatic. Thus, it is not uncommon to discover these lesions during a routine dental appointment. We present herein the case of an odontogenic myxoma of the maxilla in a 24-year-old woman with a brief review of the literature, focusing on clinical symptoms, radiological presentation, differential diagnosis and surgical management of OM.

\section{Case Report}

A 24-year-old female was referred to an oral pathologist by her dentist because of an incidentally discovered right palatal mass. The patient had an unremarkable medical and social history. She did not take any medication. On physical examination, a mild right facial asymmetry was noted. Clinically, the lesion was confined to the right posterior maxilla (Figure 1). Mucosal alterations were absent. On palpation, the lesion was hard. Upper right posterior teeth were mobile and slightly displaced towards the midline. Cervical lymph nodes were within normal limits. Radiographic findings included a well-corticated, multilocular radiolucency causing expansion of the cortices. The interior aspect of the lesion was characterized by fine trabeculations, forming a right angle with its periphery (Figure 2). However, teeth displacement and resorption were present. Such radiographic features were consistent with a differential diagnosis of odontogenic myxoma, central giant cell granuloma, central mucoepidermoid carcinoma, ameloblastoma, odontogenic keratocystic tumour, and other rare entities.

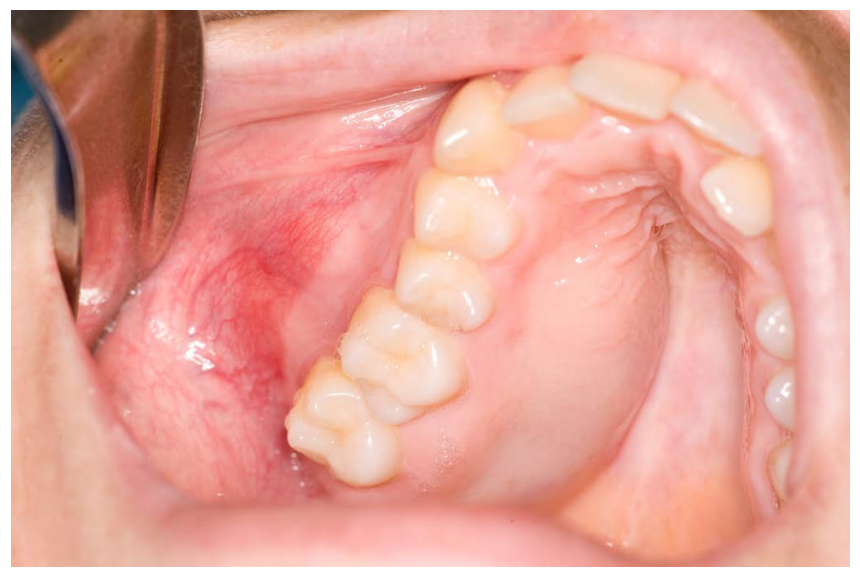

Figure 1. Right palatal mass extending to the buccal area, with medial displacement of the teeth.

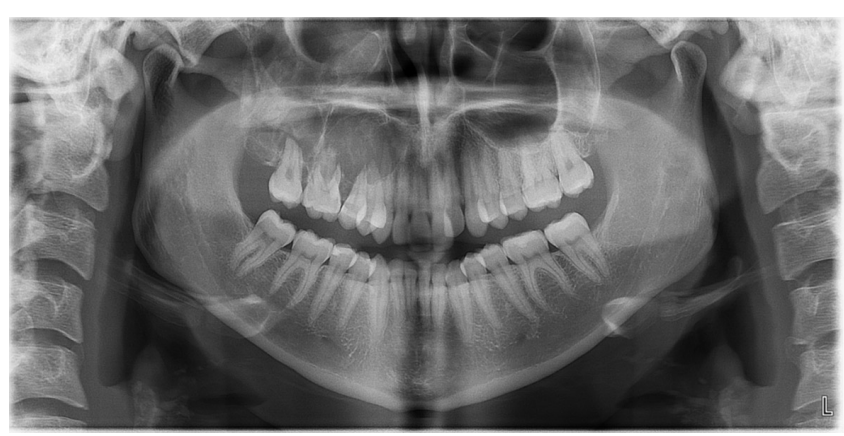

Figure 2. Dental panoramic radiograph showing a well-defined radiolucent mass with hyperdense intralesional trabecular ions, extending from the second molar to the ipsilateral lateral incisor and superiorly into the right maxillary sinus. 
A CT scan was performed and showed a $62 \mathrm{~mm} \times 35 \mathrm{~mm} \times 46 \mathrm{~mm}$ heterogeneous multilocular mass with multiple septae, originating from the right maxilla (Figure 3). The lesion completely obliterated the right maxillary sinus and extended into the right nasal cavity, sparing the nasal septum. The lesion also protruded into the facial soft tissues and extended into the right posterior ethmoidal cells, as well as the orbital floor. Tumour involved the posterior maxillary wall, without invasion of the pterygopalatine fossa.

On biopsy, the specimen was greyish and gelatinous. Histologic features revealed myxoid tissue characterized by delicate collagenisation and haphazardly arranged spindled stromal cells. Odontogenic rests was absent. Cytologic atypia and necrosis were absent. The histologic diagnosis was consistent with that of an odontogenic myxoma (Figure 4).

The patient underwent an extended right radical maxillectomy with immediate reconstruction of the orbital rim and floor in October 2013 (Figure 5). A Weber-Ferguson with subciliary incision was used as an approach. A mini plate was contoured to the inferior orbital rim to have appropriate facial projection. Osteotomies were accomplished with a reciprocating saw with minimal margins. No curettage was necessary as the specimen included the entire tumour. The specimen was well-delimited by the sinus mucosa. A scapular osteo-muscular flap was used, with tunelization of the pedicle through the cheek. Patient did not require tracheostomy. The patient left the hospital on the eleventh post-operative day. Regular follow-up was accomplished on a regular threemonth basis and follow-up CT-scan obtained one year after surgery did not reveal any sign of recurrence.

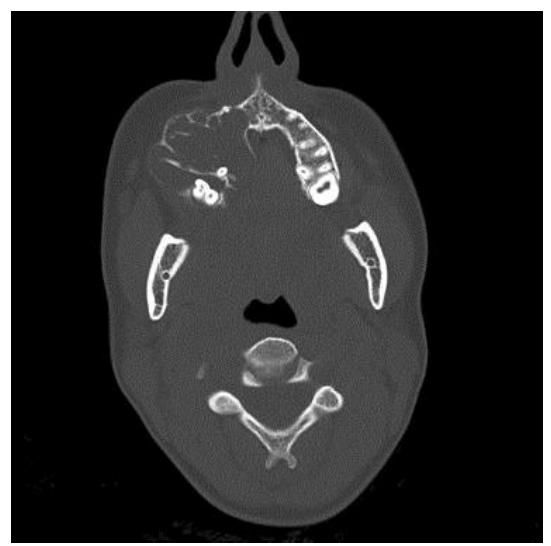

(a)

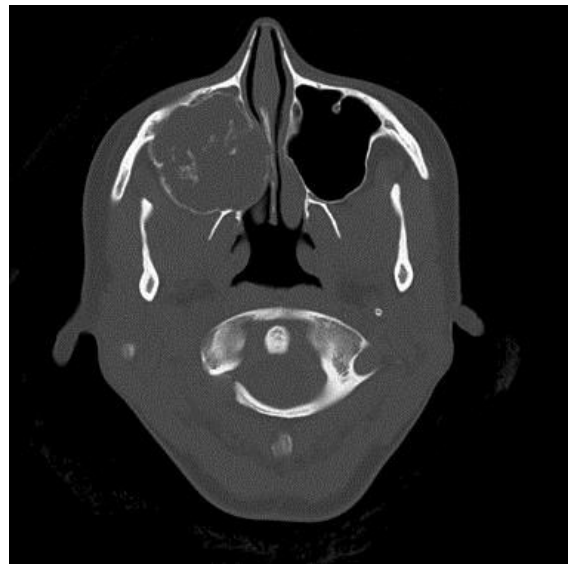

(b)

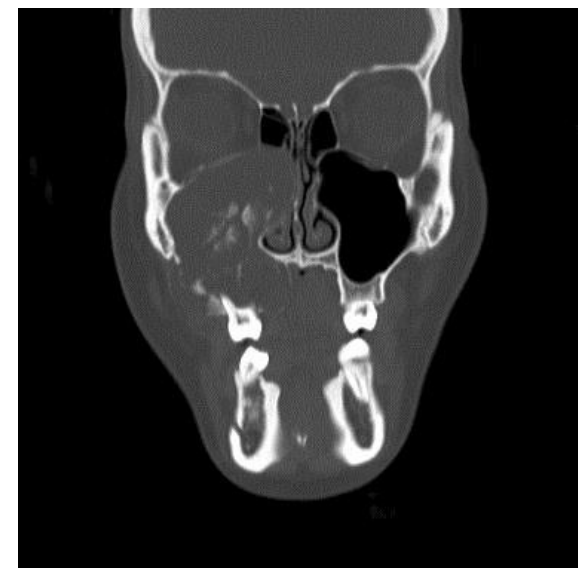

(c)

Figure 3. CT scan of the maxilla. (a) Axial view showing a heterogeneous, well-defined mass with perpendicular septae, originating from the right maxilla. The mass extends horizontally from the last molar to the ipsilateral lateral incisor with invasion into the right maxillary sinus and surrounding soft tissues. Teeth displacement is also present; (b) Mass extending laterally to the temporal process of the zygoma and posteriorly to the pterygoid plates; (c) Coronal view showing the invasion of the right nasal cavity and the right posterior ethmoidal cells and thinning of the orbital floor. 


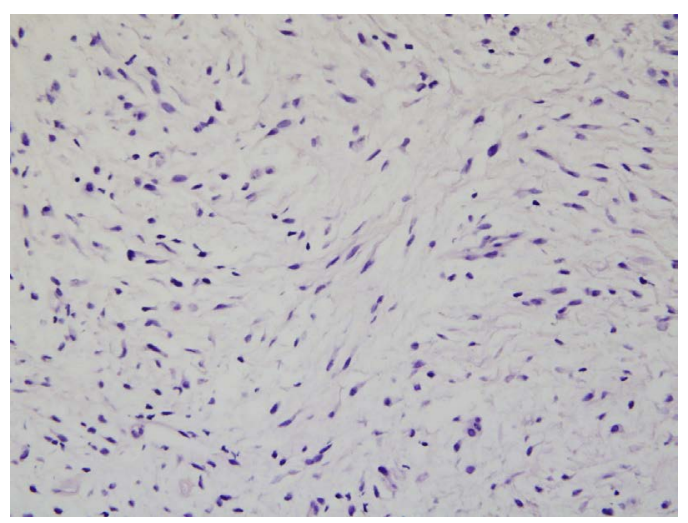

Figure 4. H\&E, 20×. Histologic appearance of the specimen.

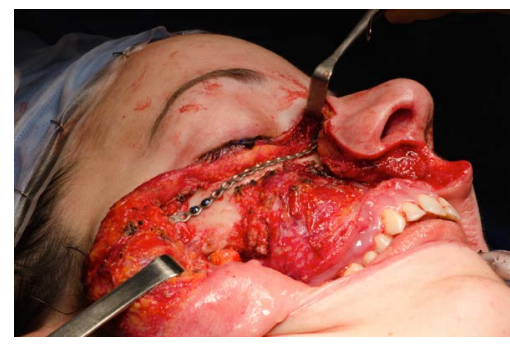

(a)

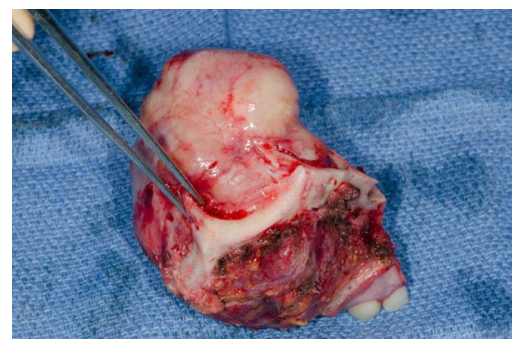

(b)

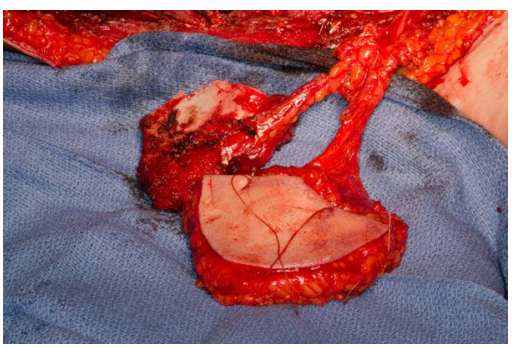

(c)

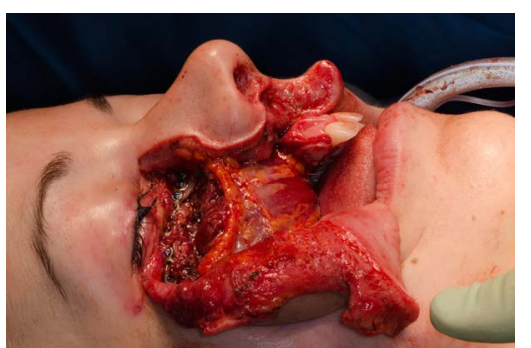

(d)

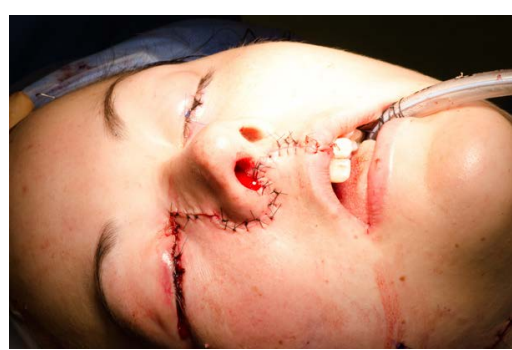

(e)

Figure 5. Peri-operative photos; Weber-Ferguson incision. (a) Reconstruction of inferior orbital rim; (b) Maxillary specimen with sinusal mucosa. Note resorption of orbital floor; (c) Scapular flap harvest; (d) Final position of osteo-muscular graft; (e) Weber-Ferguson incision closure with preserved facial aesthetic.

\section{Discussion}

OMs are rare tumours of the jaws with female predilection, and generally occur in the second to fourth decades of life. Our case report presented a 24-year-old woman, which is in conformity with the typical demographics [8] [10]. The posterior mandible is more often involved. In maxillary tumours, the sites of predilection are the alveolar and zygomatic processes [11]. Although benign, OM can be locally invasive and aggressive. The tumour is generally slow-growing and mitoses are rarely seen [12]. However, few cases of rapidly growing OMs have been described. OMs are poorly delimited and non-encapsulated tumours, which contribute to their high recurrence rate [13]. Lesions of the maxilla have also been described as being more aggressive than those of the mandible because of contiguity and easy extension into surrounding vital structures [7].

While the tumour expands, it remains asymptomatic for most patients [7]. When present, the symptoms, as reported in the literature, can be classified according to their expansion to 1) the palate and oral cavity, 2) the sinuses and nasal cavity and 3) the orbit [4] [6]. Symptoms are summarized in Table 1. Despite the massive size and nasal involvement of the lesion, our patient did not complain of epistaxis nor nasal obstruction. Therefore, asymptomatic patients may delay the time of diagnosis and result in bigger expansion of the tumour before proper 
Table 1. Site-specific symptoms of odontogenic myxomas.

\begin{tabular}{ccc}
\hline Palate and oral cavity & Sinuses and nasal cavity & Orbit \\
\hline Mass & Nasal obstruction & Exophtalmus \\
Pain, erythema, oedema & Sinusal or paranasal pain & Diplopia \\
Unerupted or absent tooth & Recurrent epistaxis & Lacrymal duct obstruction \\
Tooth displacement or mobility & Nasal discharge & \\
Malocclusion & Sinusitis & \\
Paresthesia & \\
Bone perforation & \\
Facial or jaw asymmetry & \\
Trismus & \\
Dysphagia & \\
Dysphonia & \\
Erosion or ulceration of mucosa (rare)
\end{tabular}

diagnosis and management.

Radiographic findings of OM are variable, which makes the diagnosis of OM hard based on radiology alone, although a multilocular radiolucent pattern with fine septae is suggestive of OM. Asaumi et al. have published a classification of odontogenic myxoma of the maxilla based on appearances on CT scan and MRI [14]. Zhang et al. have reported a 6-type classification for radiographic findings of OM after reviewing conventional radiographs of 41 cases of OM involving either the mandibule or the maxilla [15]. These two classifications are compared in Table 2. This illustrates the considerable variety in the radiographic appearance of OM. Thus, a single classification might not be feasible. The final diagnosis is confirmed histologically.

Surgical management of OM is the treatment of choice as the tumour is not radiosensitive. Reconstruction can be immediate or delayed. Some authors suggest the surgical approach should depend on the tumour size [4] [13]. Reported techniques vary from conservative treatments such as enucleation and curettage to radical resection with clear margins to up to $2 \mathrm{~cm}$ [2] [16] [17]. Because OM is non-encapsulated tumour, complete removal of OM tissues with conservative treatment can be difficult as the tumour can infiltrate the surrounding tissues without causing immediate radiographically visible changes [11].

Recurrence of OMs is directly related to the location, size and surgical approach and ranges from 10\% to 33\% in the literature [2] [4] [13] [18]. Predictive histologic factors have yet to be identified. As would be expected, recurrence rates have been reported to be higher with enucleation and curettage compared to radical resection [3]. One might be tempted to select a conservative approach; however, given the lack of an identifiable capsule, bone infiltration by tumour and increased risk of tumour seeding with surgical manipulation, en bloc resection with conservative clear margins is the preferred approach. More research is needed on the correlation between recurrence rates and surgical approaches. Cases of recurrence have been reported up to fifteen years after surgery [16]. Patients with OM of the maxilla should initially have close clinical follow-ups and annual follow-ups thereafter [17].

\section{Conclusion}

This was a case of a 24-year-old woman presenting with an asymptomatic OM of the right maxilla, with expansion to the surrounding soft tissues of the face, the maxillary sinus, the nasal cavity and the ethmoidal cells. Our patient underwent an extended right radical en bloc maxillectomy with immediate reconstruction. OMs are asymptomatic and may delay the time of diagnosis and therefore result in bigger expansion of the tumour before proper diagnosis and management. OM has variable radiographic findings, but fine trabeculations forming a right angle with cortical bone are highly suggestive of odontogenic myxoma. A biopsy is required to confirm the 
Table 2. Comparison of radiographic findings of OM.

\begin{tabular}{ll}
\hline \multicolumn{1}{c}{ Asaumi et al. [14] } & \multicolumn{1}{c}{ Zhang et al. [15] } \\
\hline $\begin{array}{l}\text { Type I: Osteolytic expansile lesions with mild enhancement of the solid } \\
\text { portion of the mass in the myxoma of the mandible }\end{array}$ & Type I: unilocular \\
Type II: Bony expansion and thinning of cortical plates with strong & $\begin{array}{l}\text { Type II: multilocular (including honeycomb, } \\
\text { soap bubble, and tennis racquet patterns) } \\
\text { enhancement of the mass lesion in the anterior maxilla }\end{array}$ \\
$\begin{array}{l}\text { Type III: A soft tissue mass with bone destruction and thinning, and strands of } \\
\text { fine lace-like density representing ossifications in the maxillary sinus. Borders } \\
\text { can also range from well-defined corticated borders to diffuse borders, with } \\
\text { the majority being well-defined borders }\end{array}$ & $\begin{array}{l}\text { Type III: involvement of local alveolar bone } \\
\end{array}$ \\
& $\begin{array}{l}\text { Type IV: involvement of the maxillary sinus } \\
\text { Type V: osteolytic destruction } \\
\text { Type VI: a mix of osteolytic destruction and } \\
\text { osteogenesis }\end{array}$
\end{tabular}

diagnosis. A radical surgical approach is recommended for OM of the maxilla because of their higher reported recurrence rate. A long term follow-up is needed [3].

\section{References}

[1] Thoma, K.H. and Goldman, H.M. (1947) Central Myxoma of the Jaw. American Journal of Orthodontics and Oral Surgery, 33, B532-B540. http://dx.doi.org/10.1016/0096-6347(47)90315-3

[2] Daif, E.T. (2013) Prognostic Evaluation of Preserving Palatal Mucosa after Resection of Maxillary Myxoma: 10 Years' Follow-Up. Journal of Craniofacial Surgery, 24, e361-e365. http://dx.doi.org/10.1097/SCS.0b013e3182902f2a

[3] Cankaya, M.A.E., Erdem, M.A., Bilgic, B. and Firat, D. (2013) Myxofibroma of the Maxilla, Current Concepts, and Differential Diagnosis. Journal of Dental Sciences, 1-4.

[4] Simon, E.N., et al. (2004) Odontogenic Myxoma: A Clinicopathological Study of 33 Cases. International Journal of Oral and Maxillofacial Surgery, 33, 333-337. http://dx.doi.org/10.1016/j.ijom.2003.12.004

[5] Sriram, G. and Shetty, R.P. (2008) Odontogenic Tumors: A Study of 250 Cases in an Indian Teaching Hospital. Oral Surgery, Oral Medicine, Oral Pathology, Oral Radiology, and Endodontology, 105, e14-e21. http://dx.doi.org/10.1016/j.tripleo.2008.02.021

[6] Regezi, J.A., Kerr, D.A. and Courtney, R.M. (1978) Odontogenic Tumors: Analysis of 706 Cases. Journal of Oral Surgery, 36, 771-778.

[7] Shah, A., et al. (2011) Odontogenic Myxoma of the Maxilla: A Report of a Rare Case and Review on Histogenetic and Diagnostic Concepts. National Journal of Maxillofacial Surgery, 2, 189-195. http://dx.doi.org/10.4103/0975-5950.94480

[8] Friedrich, R.E., et al. (2012) Radiographic Findings of Odontogenic Myxomas on Conventional Radiographs. Anticancer Research, 32, 2173-2177.

[9] Barros, R.E., Dominguez, F.V. and Cabrini, R.L. (1969) Myxoma of the Jaws. Oral Surgery, Oral Medicine, Oral Pathology, 27, 225-236. http://dx.doi.org/10.1016/0030-4220(69)90177-7

[10] Effiom, O.A., Adewole, R.A. and Odukoya, O. (2011) Clinicopathological Characteristics of Odontogenic Myxoma in Nigerians. West African Journal of Medicine, 30, 255-261.

[11] Zanetti, L.S., et al. (2011) Conservative Treatment of Odontogenic Myxoma. Journal of Craniofacial Surgery, 22, 1939-1941. http://dx.doi.org/10.1097/SCS.0b013e318211519e

[12] Arul, A.S., Verma, S. and Verma, R. (2013) Infiltrative Odontogenic Myxoma of the Posterior Maxilla: Report of a Case. Journal of Natural Science, Biology and Medicine, 4, 484-487. http://dx.doi.org/10.4103/0976-9668.116990

[13] Boffano, P., et al. (2011) Surgical Treatment of Odontogenic Myxoma. Journal of Craniofacial Surgery, 22, 982-987. http://dx.doi.org/10.1097/SCS.0b013e3182101400

[14] Asaumi, J., et al. (2001) Odontogenic Myxoma of Maxillary Sinus: CT and MR-Pathologic Correlation. European Journal of Radiology, 37, 1-4. http://dx.doi.org/10.1016/S0720-048X(00)00229-1

[15] Zhang, J., et al. (2007) Radiographic Examination of 41 Cases of Odontogenic Myxomas on the Basis of Conventional Radiographs. Dentomaxillofacial Radiology, 36, 160-167. http://dx.doi.org/10.1259/dmfr/38484807

[16] Kansy, K., et al. (2012) Odontogenic Myxoma: Diagnostic and Therapeutic Challenges in Paediatric and Adult Patients-A Case Series and Review of the Literature. Journal of Cranio-Maxillo-Facial Surgery, 40, 271-276. http://dx.doi.org/10.1016/j.jcms.2011.04.009 
[17] Jaswal, A., et al. (2008) Recurrent Odontogenic Myxoma of Maxilla: A Diagnostic and Operative Dilemma. Indian Journal of Otolaryngology and Head Neck Surgery, 60, 41-44. http://dx.doi.org/10.1007/s12070-008-0013-1

[18] Leiser, Y., Abu-El-Naaj, I. and Peled, M. (2009) Odontogenic Myxoma-A Case Series and Review of the Surgical Management. Journal of Cranio-Maxillo-Facial Surgery, 37, 206-209. http://dx.doi.org/10.1016/j.jcms.2008.10.001 
Scientific Research Publishing (SCIRP) is one of the largest Open Access journal publishers. It is currently publishing more than 200 open access, online, peer-reviewed journals covering a wide range of academic disciplines. SCIRP serves the worldwide academic communities and contributes to the progress and application of science with its publication.

Other selected journals from SCIRP are listed as below. Submit your manuscript to us via either submit@scirp.org or Online Submission Portal.
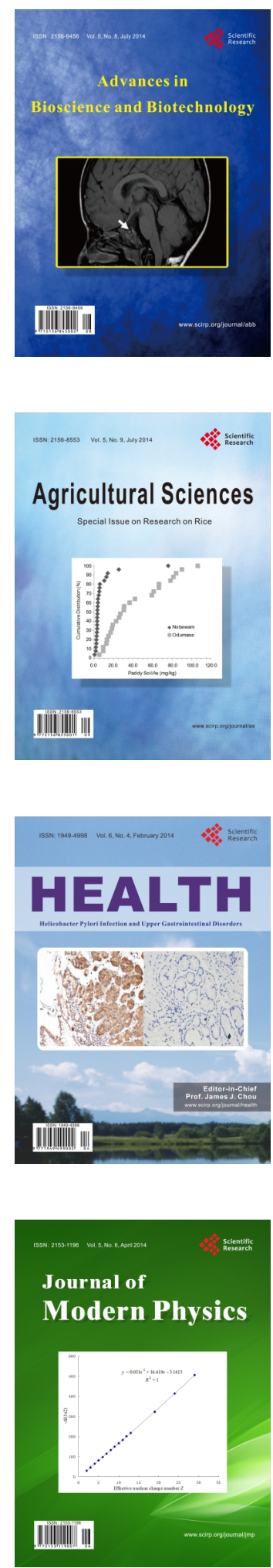
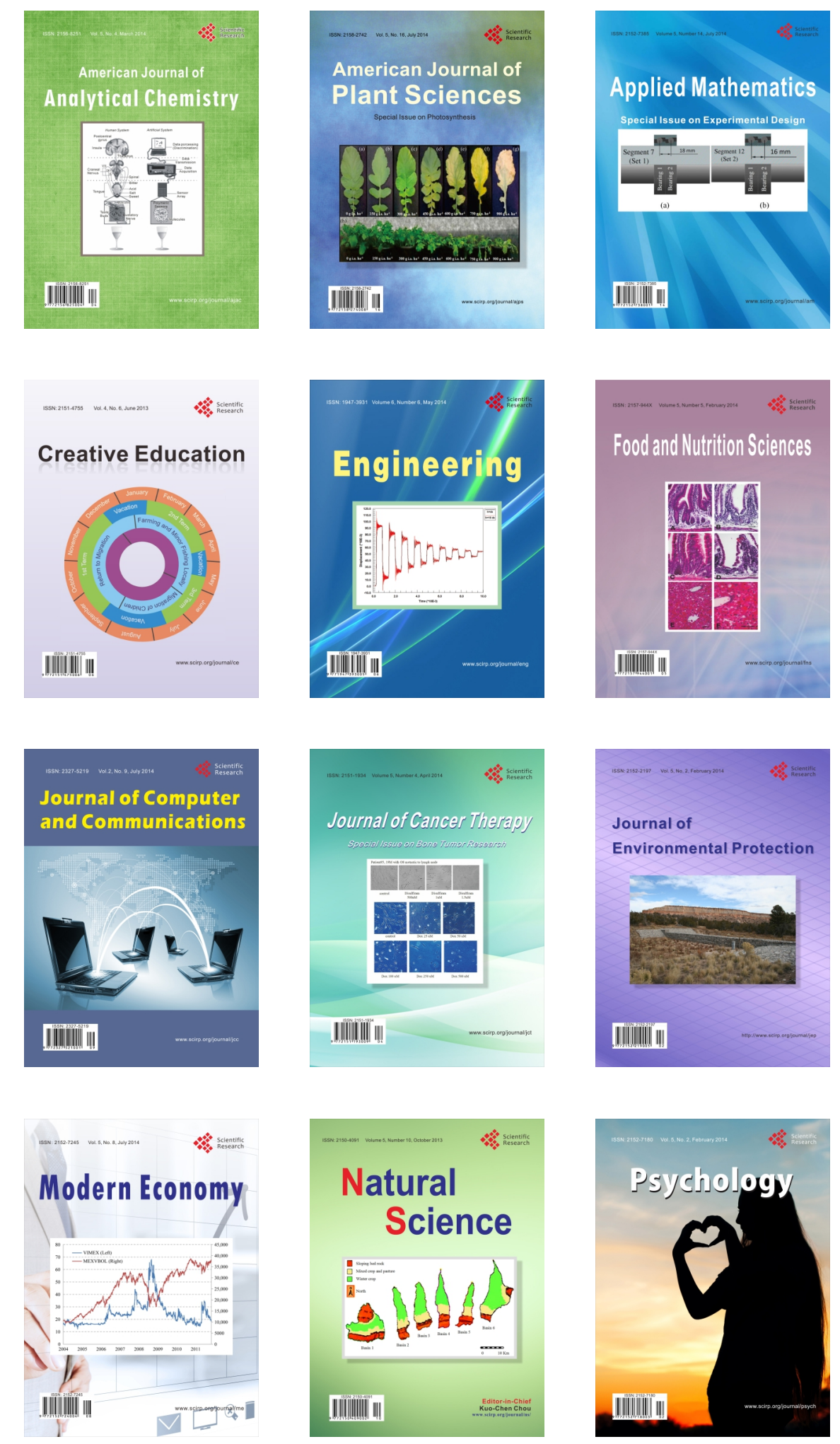